\title{
A pseudopyloric channel created by repeated blind post-pyloric feeding tube placement
}

A 58-year-old man with esophageal cancer underwent a transhiatal esophagectomy and presented to the surgical intensive care unit (SICU) with progressively worsening shortness of breath 14 days after his surgery. The patient was found to have a left empyema, possibly from an anastomotic leak, and underwent a left video-assisted thoracotomy (VATS) decortication and empyema drainage, and endoscopic placement of two tandem fully covered esophageal stents. While recovering in the SICU, the patient had multiple episodes of agitation that resulted in his pulling out his post-pyloric feeding tube. The tube was reinserted blindly at the bedside multiple times without any obvious difficulty or complications.

On one occasion, after the patient had pulled out his nasojejunal feeding tube, the tip of the tube was noted to be missing and subsequent radiographs showed that it had likely caught on one of the esophageal stents. The patient underwent endoscopy to retrieve this retained segment and for endoscopic placement of a new feeding tube. During this endoscopy, it was noted that a false tract had been created through the muscle of the pylorus, probably from a forced feeding tube insertion (৫ Fig. 1).

Insertion of post-pyloric feeding tubes has been associated with various complications, including but not limited to bleeding [1], injury to the soft tissue in the nasopharynx and pharynx [2], esophageal and enteric perforations $[3,4]$, and malposition into the lungs and brain [5]. A satisfactory position on a portable bedside radiograph of the abdomen usually convincingly rules out malposition.

We describe an incidentally detected complication of post-pyloric tube placement, wherein a false tract in the form of a pseudopyloric channel was created, presumably from multiple attempts at feeding tube placement, though it is unclear when creation of the false tract might have occurred. To our knowledge, such a complication of blind post-pyloric feeding tube placement has not previously been described in the literature.

Endoscopy_UCTN_Code_CPL_1AH_2AJ

\section{Competing interests: None}

\section{Kunal Karamchandani ${ }^{1}$, John M. Leve- nick $^{2}$, Charles E. Dye ${ }^{2}$, David Campbell ${ }^{3}$}

${ }^{1}$ Department of Anesthesiology, Penn State Hershey Medical Center, Hershey, Pennsylvania, USA

${ }^{2}$ Department of Gastroenterology, Penn State Hershey Medical Center, Hershey, Pennsylvania, USA

${ }^{3}$ Heart and Vascular Institute, Cardiothoracic Surgery, Penn State Hershey Medical Center, Hershey, Pennsylvania, USA

\section{References}

1 Metheny NA, Meert KL, Clouse RE. Complications related to feeding tube placement. Curr Opin Gastroenterol 2007; 23: 178-182

2 Filippi L, Pezzati M, Poggi C. Use of polyvinyl feeding tubes and iatrogenic pharyngo oesophageal perforation in very-low-birth weight infants. Acta Paediatr 2005; 94: $1825-1828$

3 Al-Sawan RM, Soni AL, Al-Saleh Q. Esophageal perforation in neonates: a report of seven cases from Kuwait. Kuwait Med J 2005; 37: $203-206$

4 Gluer S, Schmidt AI, Jesch NK et al. Laparoscopic repair of neonatal gastric perforation. J Pediatr Surg 2006; 41: e57-e58

5 Sorokin $R$, Gottlieb JE. Enhancing patient safety during feeding-tube insertion: a review of more than 2000 insertions. J Parenter Enter Nutr 2006; 30: 440 - 445

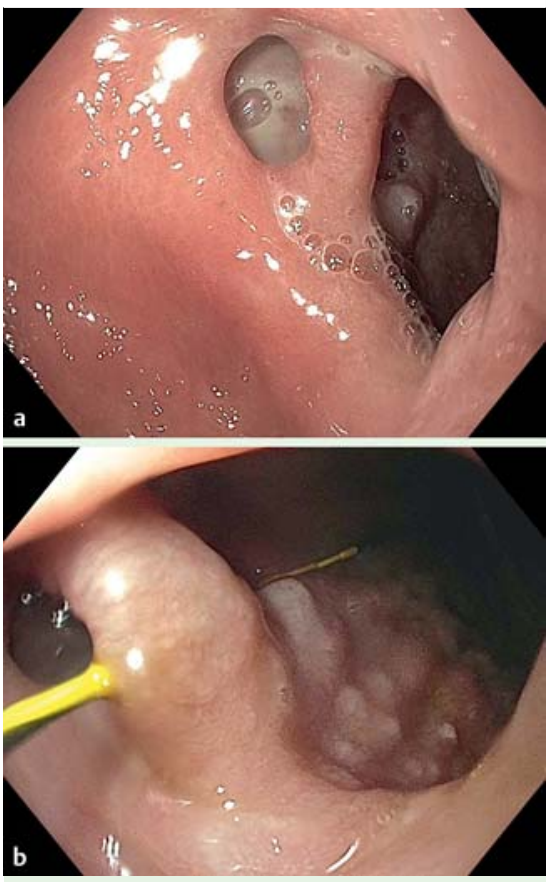

Fig. 1 Endoscopic views in an intensive care unit patient who had undergone multiple blind insertions of a post-pyloric feeding tube showing: a a pseudopyloric channel adjacent to the pylorus; b the pseudopyloric channel with a Jagwire positioned to demonstrate the through-and-through pyloric disruption.

Bibliography

DoI http://dx.doi.org/ 10.1055/s-0034-1393154

Endoscopy 2015; 47: E525

(c) Georg Thieme Verlag KG

Stuttgart · New York

ISSN 0013-726X

Corresponding author

John Levenick, MD

Department of Gastroenterology

Penn State University Milton S. Hershey

Medical Center

Hershey, PA-17036

USA

jlevenick@hmc.psu.edu 